\title{
KD025, an anti-adipocyte differentiation drug, enhances the efficacy of conventional chemotherapeutic drugs in ABCG2-overexpressing leukemia cells
}

\author{
WEN JING $^{1 *}$, XUERONG ZHANG ${ }^{1 *}$, RUIXIA CHEN ${ }^{1}$, XIJIU YE $^{1}$, MAO ZHOU $^{1}$, \\ WEIXING LI ${ }^{1}$, WENCHAN YAN ${ }^{1}$, XIUXIU XUYUN ${ }^{2}$ and JUN PENG ${ }^{1}$ \\ Departments of ${ }^{1}$ Anesthesiology and ${ }^{2}$ Hepatobiliary Surgery, Sun Yat-Sen Memorial Hospital, \\ Sun Yat-Sen University, Guangzhou, Guangdong 510220, P.R. China
}

Received April 4, 2020; Accepted August 20, 2020

DOI: $10.3892 / \mathrm{ol} .2020 .12172$

\begin{abstract}
Most patients with advanced leukemia eventually die from multidrug resistance (MDR). Chemotherapy-resistant leukemia cells may lead to treatment failure and disease relapse. Overexpression of ATP-binding cassette subfamily G member 2 (ABCG2) leads to MDR, which serves as a potential biomarker and target of therapeutic intervention for leukemia cells. Targeting ABCG2 is a potential strategy for selective therapy and eradicate MDR cells, thus improving malignant leukemia treatment. KD025 (SLx-2119) is a novel Rho-associated protein kinase 2-selective inhibitor, which has been shown to inhibit adipogenesis in human adipose-derived stem cells and restore impaired immune homeostasis in autoimmunity therapy. The present study demonstrated that KD025 improved the efficacy of antineoplastic drugs in ABCG2-overexpressing leukemia cells and primary leukemia blast cells derived from patients with leukemia. Moreover, KD025 significantly inhibited the efflux of $\left[{ }^{3} \mathrm{H}\right]$-mitoxantrone and hence accumulated higher levels of $\left[{ }^{3} \mathrm{H}\right]$-mitoxantrone in HL60/ABCG2 cells. However, mechanistic research indicated that KD025 did not alter the protein levels and subcellular locations of ABCG2. KD025 may restrain the efflux activity of ABCG2 by obstructing ATPase activity. Taken together,
\end{abstract}

Correspondence to: Miss Xiuxiu Xuyun, Department of Hepatobiliary Surgery, Sun Yat-Sen Memorial Hospital, Sun Yat-Sen University, 107 Yanjiang West Road, Guangzhou, Guangdong 510220, P.R. China

E-mail: xuyxx@mail.sysu.edu.cn

Dr Jun Peng, Department of Anesthesiology, Sun Yat-Sen Memorial Hospital, Sun Yat-Sen University, 107 Yanjiang West Road, Guangzhou, Guangdong 510220, P.R. China

E-mail: pengjun2@mail.sysu.edu.cn

${ }^{*}$ Contributed equally

Key words: KD025, ATP-binding cassette subfamily G member 2, multidrug resistance, leukemia
KD025 can sensitize conventional antineoplastic drugs in ABCG2-overexpressing leukemia cells by blocking the pump function of ABCG2 protein. The present findings may provide a novel and useful combinational therapeutic strategy of KD025 and antineoplastic drugs for leukemia patients with ABCG2-mediated MDR.

\section{Introduction}

Combination medicine treatment typically only results in short-term effects in the treatment of malignant leukemia (1). The combination of fludarabine, cytarabine, granulocyte colony-stimulating factor and idarubicin is traditionally used for standard induction regimens for the treatment of leukemia (2). Unfortunately, the use of various chemotherapeutics for the treatment malignant leukemia has failed to improve the overall survival, where only $40 \%$ of patients with leukemia achieve 5-year survival (3). The reason behind these modest results is considered to be caused by the combined use of multiple drugs, which eventually leads to intrinsic or acquired multidrug resistance (MDR) (4). MDR remains a formidable challenge for the successful treatment of leukemia and is the major cause resulting in relapse of leukemia (5). Therefore, MDR has become a potential target for therapeutic intervention. A number of studies reported that the most common cause of MDR is the abnormally high expression of ATP-binding cassette (ABC) transporters in leukemia cells $(6,7)$. In fact, it was shown that the overexpression of $\mathrm{ABCB} 1, \mathrm{ABCC} 1$ and ABCG2 was involved in the efflux of various antitumor agents out of the cells (8). These proteins have the ability to transport a plethora of chemotherapeutics with diverse structures and functions outside of the cells. Antagonizing these transporters has been identified to prevent drug efflux, thereby increasing the accumulation of the drug inside the cells and provide a more effective treatment for patients with leukemia (9). Therefore, $\mathrm{ABC}$ transporters have been proposed as promising targets to circumvent drug resistance and enhance the therapeutic efficacy of chemotherapeutics.

Recently, ABCG2 has received increasing attention due to its mutable pharmacological binding sites (10). Evidence suggested that the upregulation of the ABCG2 gene may be 
closely associated with the high recurrence rate and adverse therapeutic response of hematological malignancies (11). For instance, the latest data obtained from 178 elderly patients with acute myeloid leukemia (AML) revealed that a subset of samples with the worst overall survival rate and the highest incidence of drug-resistant disease had upregulated expression levels of ABCG2 (12). Furthermore, ABCG2 was recognized as a documented marker for the side population (SP) phenotype, which is highly rich in leukemia stem cells (LSCs) and protects LSCs from antineoplastic agents (13). These results suggested that ABCG2 may be a potential treatment target for MDR in leukemia.

As a potential therapeutic target, effectively exploiting ABCG2 transporter inhibitors is the most commonly adopted approach to overcome MDR. Unfortunately, to date, the majority of ABCG2 inhibitors have failed in clinical trials due to their unfavorable side effects, insufficient therapeutic effects or unpredictable pharmacokinetic interactions (14). Thus, determining novel functions of drugs already in clinical use is one of the most imperative strategies for identifying safer and more efficient ABCG2 inhibitors.

KD025 (also known as SLx-2119) is a novel selective inhibitor of Rho-associated protein kinase 2 (ROCK) 2, which is 200-fold more selective for ROCK-2 than ROCK-1 (15). ROCK was reported to serve an important role in numerous intracellular processes and the aberrant activation of the Rho-kinase pathway has been proven to contribute to cardiovascular, renal and neurological disorders in non-hematopoietic cells (16). In addition, a study reported that KD025 could restrain adipogenesis in 3T3-L1 cells by regulating key pro-adipogenic factors; the results further implied that KD025 may be a potential obesity agent (17). Data from Zanin-Zhorov et al (18) indicated that KD025 may restore impaired immune homeostasis and serve a role in autoimmunity therapy.

Upon screening for novel ABCG2 inhibitors in leukemia cells, KD025 was discovered to markedly potentiate the efficacy of conventional chemotherapeutic agents in ABCG2-overexpressing leukemia cells and primary leukemia blast cells derived from patients with leukemia. In addition, KD025 significantly inhibited the efflux of $\left[{ }^{3} \mathrm{H}\right]$-mitoxantrone and the accumulation of higher levels of $\left[{ }^{3} \mathrm{H}\right]$-mitoxantrone in HL60/ABCG2 cells. Thus, the present study aimed to determine the effects of KD025 on the protein expression levels and cellular location of ABCG2 in leukemia cells. The findings of the current study may provide a novel perspective for overcoming MDR in malignant leukemia.

\section{Materials and methods}

Chemicals and reagents. KD025 was purchased from Selleck Chemicals. Mitoxantrone, topotecan, cisplatin and fumitremorgin C (FTC) were purchased from Sigma-Aldrich (Merck $\mathrm{KGaA}$ ). RPMI 1640, bovine serum albumin (BSA), fetal bovine serum (FBS), penicillin/streptomycin and $0.25 \%$ trypsin were purchased from HyClone (Cytiva). Primary monoclonal antibody against ABCG2 (cat. no. MAB4145; clone BXP-34) and AlexaFluor488-conjugated goat anti-mouse IgG secondary antibody (cat. no. A-10684) were purchased from Thermo Fisher Scientific, Inc. HRP-conjugated rabbit anti-sheep IgG secondary antibody (cat. no. AP147P) was purchased from
Sigma-Aldrich (Merck KGaA). Primary antibody against GAPDH (cat. no. KC-5G4) was purchased from Aksomics Inc. $\left[{ }^{3} \mathrm{H}\right]$-mitoxantrone $(4 \mathrm{Ci} / \mathrm{mmol})$ was purchased from Moravek Biochemicals Inc. DMSO, MTT, DAPI and paraformaldehyde were purchased from Sigma-Aldrich (Merck $\mathrm{KGaA}$ ). Mitoxantrone, topotecan and FTC were used in place of KD025 as positive controls to confirm the mechanism of drug resistance in leukemia cell line models. Cisplatin (a non-substrate of ABCG2) was used as a negative control.

Cell lines and culture. The human leukemia cell lines HL60 and K562 were purchased from the Institute of Hematology \& Blood Diseases Hospital, Chinese Academy of Medical Sciences \& Peking Union Medical College. P388 cell lines were purchased from the Cell Bank, Institute of Cell Biology, Chinese Academy of Sciences. HL60/ABCG2, K562/ABCG2, and P388/ABCG2 cells (which overexpress ABCG2) were established by the transduction of HL60, K562 and P388 cells, respectively, with a Ha-breast cancer resistant protein (BCRP) retrovirus that carried Myc-tagged human BCRP (ABCG2) cDNA in the Ha retrovirus vector $(19,20)$. HL60, HL60/ABCG2, K562 and K562/ABCG2 cell lines were cultured in RPMI 1640 containing 10\% FBS, $100 \mathrm{U} / \mathrm{ml}$ penicillin and $100 \mathrm{U} / \mathrm{ml}$ streptomycin at $37^{\circ} \mathrm{C}$ with $5 \% \mathrm{CO}_{2}$.

Cytotoxicity evaluation by MTT assay. MTT (purity 99.59\%) reagent was used to determine the cell sensitivity to drugs with minor modifications as described previously (21). The $\mathrm{IC}_{50}$, which was defined as the drug concentration resulting in $50 \%$ cell death, was calculated from survival curves using the Bliss method. Cells were collected and seeded in 96 -well plates with appropriate density $\left(5 \times 10^{3}\right.$ cells/well in $160 \mu \mathrm{l}$ medium). After plating for $24 \mathrm{~h}$ at $37^{\circ} \mathrm{C}$, cells were pre-incubated with $0.25,0.5$ and $1 \mu \mathrm{M}$ KD025 for another $72 \mathrm{~h}$ at $37^{\circ} \mathrm{C}$. Subsequently, the cells were treated with a range of concentrations of chemotherapeutic agents by 2 -fold dilution (mitoxantrone range, $0.5-50 \mu \mathrm{M}$; topotecan range, $0.5-50 \mu \mathrm{M}$; and cisplatin range, $0.5-50 \mu \mathrm{M}$ ) for another $68 \mathrm{~h}$ at $37^{\circ} \mathrm{C}$, and $5 \mathrm{mg} / \mathrm{ml} \mathrm{MTT} \mathrm{(20 \mu l/well)} \mathrm{was} \mathrm{added} \mathrm{to} \mathrm{the}$ cells and further incubated for $4 \mathrm{~h}\left(37^{\circ} \mathrm{C}\right)$. Subsequently, the medium was discarded, and $200 \mu 1$ DMSO was added to each well to dissolve the formazan product formed from the metabolism of MTT. The absorbance was determined at a wavelength of $540 \mathrm{~nm}$ with a background subtraction at $670 \mathrm{~nm}$ using a Model 550 microplate reader (Bio-Rad Laboratories, Inc.) (22). The resistance fold-change was calculated by dividing the $\mathrm{IC}_{50}$ values of substrates in the presence or absence of the inhibitor by the $\mathrm{IC}_{50}$ of the parental cells without inhibitor treatment (23).

Patient samples. The present study was approved by the Ethics Review Committee of Sun Yat-Sen University. Bone marrow blood ( $3 \mathrm{ml}$ ) was obtained from nine patients diagnosed with AML or acute lymphoblastic leukemia (ALL) according to FAB classification (24). All patients provided written informed consent. Leukemia blasts were isolated using Ficoll-Hypaque density gradient centrifugation and cultured in RPMI-1640 medium containing 20\% FBS (25). Western blotting was performed to determine ABCG2 expression levels in patient samples. 
$\left[{ }^{3} \mathrm{H}\right]$-mitoxantrone accumulation and efflux assays. Following treatment for $12 \mathrm{~h}$ with or without $0.25,0.5$ or $1 \mu \mathrm{M}$ KD025, $0.2 \mu \mathrm{M}\left[{ }^{3} \mathrm{H}\right]$-mitoxantrone was added into the and incubated for another $2 \mathrm{~h}$ at $37^{\circ} \mathrm{C}$. Subsequently, the cells were washed three times with ice-cold PBS and lysed in $10 \mathrm{mM}$ lysis buffer. The radioactivity of the cells was measured using a Packard TRI-CARB $^{\circledR}$ 1900CA liquid scintillation analyzer from PerkinElmer, Inc.

Following the accumulation assay, the cells were incubated in the presence or absence of $0.25,0.5$ or $1 \mu \mathrm{M}$ KD025 and $2.5 \mu \mathrm{M}$ FTC overnight. Subsequently, the cells were suspended in PRMI 1640 medium containing $0.2 \mu \mathrm{M}$ $\left[{ }^{3} \mathrm{H}\right]$-mitoxantrone with or without reversal agent at $37^{\circ} \mathrm{C}$ for $2 \mathrm{~h}$. After washing three times with ice-cold PBS, the cells were collected at various time points $(0,60,120$ and $240 \mathrm{~min})$. Each sample was placed in scintillation fluid and the radioactivity was analyzed as described previously (26).

Western blotting. Western blotting was performed to test the expression levels of ABCG2 protein after treatment with $0.25,0.5$ or $1 \mu \mathrm{M}$ KD025 for $48 \mathrm{~h}$ or with $2.5 \mu \mathrm{M}$ KD025 for $0,24,36,48$ and $72 \mathrm{~h}$ (27). Following $12 \mathrm{~h}$ of incubation with $0.25,0.5$ or $1 \mu \mathrm{M} \mathrm{KD} 025$, whole cells were harvested and washed twice with ice-cold PBS. Cell extracts were collected using a cell lysis buffer (PBS containing 1\% Nonidet P-40, $0.5 \%$ sodium deoxycholate, $0.1 \% \mathrm{SDS}, 100 \mathrm{mg} / \mathrm{ml} \mathrm{PMSF}$, $10 \mathrm{mg} / \mathrm{ml}$ aprotinin and $10 \mathrm{mg} / \mathrm{ml}$ leupeptin). Protein concentration was determined using a BCA Protein assay (Thermo Fisher Scientific, Inc.). Equal amounts of protein $(60 \mu \mathrm{g} / \mathrm{lane})$ were separated via $10 \%$ SDS-PAGE. The separated proteins were subsequently transferred onto nitrocellulose membranes and blocked with TBS-Tween-20 (TBST) buffer $(10 \mathrm{mmol} / \mathrm{I}$ Tris- $\mathrm{HCl}, 150 \mathrm{mmol} / \mathrm{I} \mathrm{NaCl}$ and $0.1 \%$ Tween-20; $\mathrm{pH} 8.0$ ) for $2 \mathrm{~h}$ at room temperature. The membranes were then incubated overnight at $4^{\circ} \mathrm{C}$ with primary monoclonal antibodies against ABCG2 (1:200) or GAPDH (1:1,000). After washing three times with TBST, the membranes were incubated with HRP-conjugated secondary antibody $(1: 5,000)$ for $2 \mathrm{~h}$ at room temperature. The protein-antibody complexes were then washed with TBST, and protein bands were visualized using an enhanced chemiluminescence detection system (Phototope TM-HRP Detection kit; Cell Signaling Technology, Inc.). The protein bands were analyzed using Scion Image 4.0.3 software (Scion Corporation). The protein expression levels were quantified using gray value analysis software (Image Lab 3.0; Bio-Rad Laboratories, Inc.) GAPDH was used as a loading control.

Immunofluorescence staining. Following overnight incubation in 24-well plates, $2.5 \mu \mathrm{M}$ KD025 was added to the cells and incubated for $72 \mathrm{~h}$. The cells were then fixed in 4\% paraformaldehyde for $15 \mathrm{~min}$ and permeabilized using $0.1 \%$ Triton $\mathrm{X}-100$ for $10 \mathrm{~min}$ both at room temperature, before blocking with $6 \%$ BSA for $1 \mathrm{~h}$ at room temperature. Subsequently, the cells were incubated overnight at $4^{\circ} \mathrm{C}$ with a monoclonal antibody against ABCG2 (1:500). Following incubation, the cells were washed with ice-cold PBS and incubated with AlexaFluor488-conjugated goat anti-mouse IgG secondary antibody for $1 \mathrm{~h}(1: 1,000)$. Cell nuclei were dyed with $1 \mu \mathrm{g} / \mathrm{ml}$ DAPI for $72 \mathrm{~h}$ at $4^{\circ} \mathrm{C}$ (Sigma-Aldrich; Merck
$\mathrm{KGaA}$ ). Immunofluorescence images were captured using an inverted confocal microscope in 6-8 random microscopic fields (magnification, x400; model IX70; Olympus Corporation) with IX-FLA fluorescence and a Charge-Coupled Device camera.

Statistical analysis. Statistical analysis was performed using SPSS 16.0 (SPSS, Inc.). Data are presented as the mean \pm SD of 3-5 independent experimental repeats. Statistical differences between the data were determined using one-way ANOVA and Student's t-test. One-way ANOVA was used to assess significant differences between the means of multiple groups, followed by Dunnett's post hoc test. Significant differences between two groups were evaluated using the unpaired Student's t-test. $\mathrm{P}<0.05$ was considered to indicate a statistically significant difference.

\section{Results}

KD025 markedly enhances the cytotoxicity of antitumor drugs in leukemia cells overexpressing ABCG2. HL60/ABCG2 and K562/ABCG2 cell lines were established by transfecting HL60 and K562 cells with a HaBCRP retrovirus, which were subsequently selected for treatment with $4.0 \mu \mathrm{M}$ mitoxantrone for 7 days. Prior to investigating the cytotoxicity of KD025, the expression levels of the ABCG2 protein in the transfected cell lines used in the study were confirmed using western blotting analysis, respectively. The protein expression levels of ABCG2 were overexpressed in K562/ABCG2 and HL60/ABCG2 cell lines compared with their parental cell lines HL60 and K562, respectively (Fig. 1A and $\mathrm{C}$ ).

MTT assays were subsequently performed to determine the cytotoxicity of KD025 treatment in different leukemia cell lines. As shown in Fig. $1 \mathrm{~B}$ and D, $>70 \%$ of the ABCG2-overexpressing cell lines, HL60/ABCG2 and K562/ABCG2, and their parental cell lines, HL60 and K562, survived $1 \mu \mathrm{M}$ KD025 treatment, indicating that KD025 may be used as a treatment up to a concentration of $1 \mu \mathrm{M}$. Therefore, all following antineoplastic drug combination assays were performed with $\leq 1 \mu \mathrm{M}$ KD025. Based on these findings, the $\mathrm{IC}_{50}$ of various drugs in leukemia-sensitive cells and in their resistant counterparts with or without the accompanying treatment with different concentrations of KD025 were determined (Tables I and II). The $\mathrm{IC}_{50}$ values of mitoxantrone and topotecan in HL60/ABCG2 and K562/ABCG2 cell lines were markedly higher than their respective values in HL60 and K562 cell lines $(\mathrm{P}<0.05)$. Following treatment with KD025, the cytotoxicity of mitoxantrone and topotecan significantly increased in both ABCG2-overexpressing HL60/ABCG2 and K562/ABCG2 cell lines compared with cell lines without KD025 treatment, but not in their parental HL60 or K562 cell lines. The $\mathrm{IC}_{50}$ of mitoxantrone in both HL60/ABCG2 and K562/ABCG2 cells reduced from $17.217 \pm 1.058$ to $0.891 \pm 0.042 \mu \mathrm{M}$ and from $23.581 \pm 0.59$ to $0.992 \pm 0.040 \mu \mathrm{M}$, respectively. Meanwhile, the $\mathrm{IC}_{50}$ of topotecan in HL60/ABCG2 and K562/ABCG2 cells decreased from $18.726 \pm 1.054$ to $0.975 \pm 0.039 \mu \mathrm{M}$ and from $17.995 \pm 0.661$ to $0.781 \pm 0.022 \mu \mathrm{M}$, respectively. In addition, the effect of KD025 was similar to that of $2.5 \mu \mathrm{M}$ FTC, which was sensitive to ABCG2-overexpressing cells and used as a positive control inhibitor of ABCG2. Conversely, KD025 treatment did not alter the $\mathrm{IC}_{50}$ value of cisplatin, which is not 
Table I. Effects of KD025 on reversing ABCG2-mediated MDR in HL60 and HL60/ABCG2 cells.

$\mathrm{IC}_{50} \pm \mathrm{SD}(\mu \mathrm{M})($ Resistance fold $)$

Treatment

HL60

HL60/ABCG2

\section{Mitoxantrone \\ $+0.25 \mu \mathrm{M} \mathrm{KD} 025$ \\ $+0.5 \mu \mathrm{M} \mathrm{KD} 025$ \\ $+1 \mu \mathrm{M} \mathrm{KD} 025$ \\ $+2.5 \mu \mathrm{M}$ FTC}

Cisplatin

$+1 \mu \mathrm{M} \mathrm{KD025}$

Topotecan

$+0.25 \mu \mathrm{M} \mathrm{KD} 025$

$+0.5 \mu \mathrm{M}$ KD025

$+1 \mu \mathrm{M} \mathrm{KD} 025$

$+2.5 \mu \mathrm{M}$ FTC

Cisplatin

$+1 \mu \mathrm{M} \mathrm{KD025}$

$$
\begin{gathered}
0.942 \pm 0.067(1.00) \\
0.980 \pm 0.083(1.04) \\
0.928 \pm 0.074(0.99) \\
0.937 \pm 0.081(0.99) \\
0.506 \pm 0.039(0.54)^{\mathrm{a}} \\
13.416 \pm 0.094(1.00) \\
14.003 \pm 0.113(1.04) \\
0.75 \pm 0.035(1.00) \\
0.648 \pm 0.030(0.86) \\
0.601 \pm 0.025(0.80) \\
0.475 \pm 0.017(0.63) \\
0.248 \pm 0.018(0.33)^{\mathrm{a}} \\
14.002 \pm 0.097(1.00) \\
16.051 \pm 0.147(1.15)
\end{gathered}
$$

$17.217 \pm 1.058(18.23)$

$4.404 \pm 0.089(4.29)^{\mathrm{b}}$

$1.862 \pm 0.050(1.98)^{\mathrm{b}}$

$0.891 \pm 0.042(0.95)^{\mathrm{b}}$

$0.825 \pm 0.031(0.88)^{\mathrm{b}}$

$20.173 \pm 0.920(1.50)$

$19.251 \pm 0.908(1.43)$

\begin{tabular}{|c|c|c|}
\hline Treatment & K562 & K562/ABCG2 \\
\hline Mitoxantrone & $1.536 \pm 0.027(1.00)$ & $23.581 \pm 0.59(15.16)$ \\
\hline$+0.25 \mu \mathrm{M}$ KD025 & $1.604 \pm 0.031(1.04)$ & $7.041 \pm 0.098(4.58)^{b}$ \\
\hline$+0.5 \mu \mathrm{M} \mathrm{KD} 025$ & $0.946 \pm 0.015(0.62)$ & $2.809 \pm 0.047(1.83)^{\mathrm{b}}$ \\
\hline$+1 \mu \mathrm{M} \mathrm{KD} 025$ & $0.633 \pm 0.014(0.41)^{\mathrm{a}}$ & $0.992 \pm 0.040(0.65)^{\mathrm{b}}$ \\
\hline$+2.5 \mu \mathrm{M}$ FTC & $0.482 \pm 0.018(0.31)^{\mathrm{a}}$ & $1.057 \pm 0.013(0.69)^{\mathrm{b}}$ \\
\hline Cisplatin & $16.517 \pm 1.815(1.00)$ & $17.092 \pm 1.659(1.04)$ \\
\hline$+1 \mu \mathrm{M} \mathrm{KD} 025$ & $14.672 \pm 1.539(0.89)$ & $16.590 \pm 1.731(1.00)$ \\
\hline Topotecan & $0.953 \pm 0.017(1.00)$ & $17.995 \pm 0.661$ \\
\hline$+0.25 \mu \mathrm{M} \mathrm{KD} 025$ & $0.841 \pm 0.021(0.88)$ & $6.118 \pm 0.069(6.42)^{b}$ \\
\hline$+0.5 \mu \mathrm{M} \mathrm{KD} 025$ & $0.710 \pm 0.013(0.75)$ & $2.35 \pm 0.037(2.47)^{\mathrm{b}}$ \\
\hline$+1 \mu \mathrm{M}$ KD025 & $0.551 \pm 0.013(0.58)^{\mathrm{a}}$ & $0.781 \pm 0.022(0.82)^{\mathrm{b}}$ \\
\hline$+2.5 \mu \mathrm{M}$ FTC & $0.630 \pm 0.014(0.66)^{\mathrm{a}}$ & $0.740 \pm 0.014(0.78)^{\mathrm{b}}$ \\
\hline Cisplatin & $13.915 \pm 1.489(1.00)$ & $17.620 \pm 1.857(1.27)$ \\
\hline$+1 \mu \mathrm{M} \mathrm{KD} 025$ & $15.481 \pm 1.693(1.11)$ & $16.729 \pm 1.319(1.20)$ \\
\hline
\end{tabular}

$18.726 \pm 1.054(24.97)$

$5.631 \pm 0.085(7.51)^{\mathrm{b}}$

$3.022 \pm 0.064(4.03)^{\mathrm{b}}$

$0.975 \pm 0.039(1.30)^{\mathrm{b}}$

$0.860 \pm 0.024(1.15)^{\mathrm{b}}$

$18.566 \pm 1.079(1.33)$

$19.805 \pm 1.093(1.41)$

Cell survival was determined using an MTT assay. Date are expressed as the mean \pm SD of at least three independent experiments. The resistance fold of MDR was calculated by dividing the $\mathrm{IC}_{50}$ for substrates in the presence or absence of inhibitor by the $\mathrm{IC}_{50}$ of parental cells without inhibitor. ${ }^{\mathrm{a}} \mathrm{P}<0.05$ and ${ }^{\mathrm{b}} \mathrm{P}<0.01$ vs. values obtained in absence of KD025. ABCG2, ATP-binding cassette transporter ABCG2; MDR, multidrug resistance; $\mathrm{SD}$, standard deviation.

Table II. Effects of KD025 on reversing ABCG2-mediated MDR in K562 and K562/ABCG2 cells.

$$
\mathrm{IC}_{50} \pm \mathrm{SD}(\mu \mathrm{M})(\text { Resistance fold })
$$

Cell survival was determined using an MTT assay. Date are expressed as the mean \pm SD of at least three independent experiments. The resistance fold of MDR was calculated by dividing the $\mathrm{IC}_{50}$ for substrates in the presence or absence of inhibitor by the $\mathrm{IC}_{50}$ of parental cells without inhibitor. ${ }^{\mathrm{a}} \mathrm{P}<0.05$ and ${ }^{\mathrm{b}} \mathrm{P}<0.01$ vs. values obtained in absence of KD025. ABCG2, ATP-binding cassette transporter ABCG2; MDR, multidrug resistance; $\mathrm{SD}$, standard deviation.

a substrate of ABCG2. These results suggested that KD025 may significantly potentiate the cytotoxicity of mitoxantrone and topotecan in ABCG2-overexpressing leukemia cell lines in a concentration-dependent manner. 

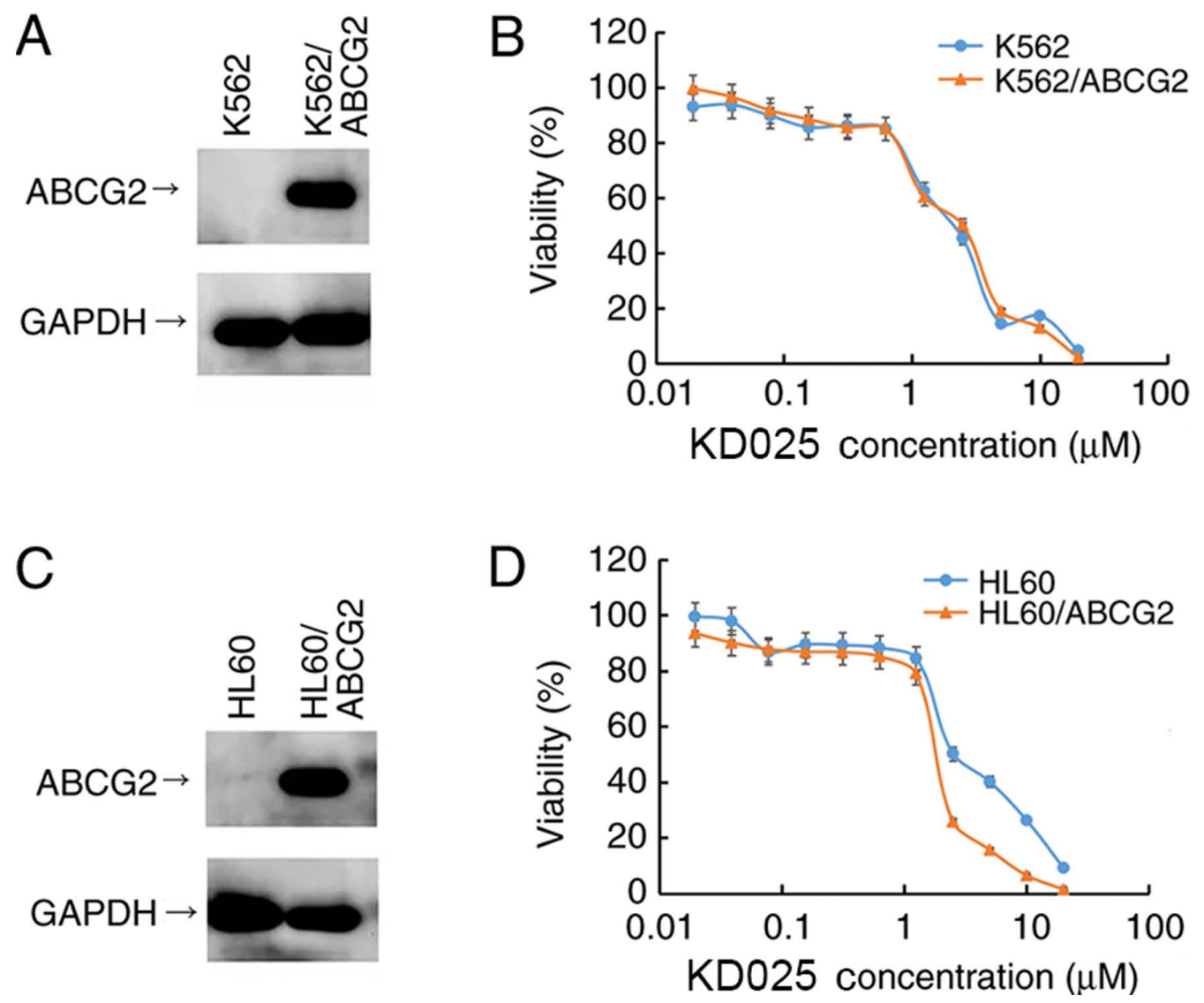

Figure 1. Cytotoxicity of KD025 in drug-resistant cell lines and their parental drug-sensitive cell lines. Expression levels of ABCG2 and cell viability of (A and B) K562 and 562/ABCG2 and (C and D) HL60 and HL60/ABCG2 cells. Data are expressed as the mean \pm standard deviation. Each result was calculated from three independent experiments. ABCG2, ATP-binding cassette transporter ABCG2.

KD025 significantly increases the cytotoxicity of mitoxantrone in patient-derived leukemic blast cells. ABCG2 is widely expressed in patients with AML and ALL (28). Thus, the expression levels of ABCG2 and the cytotoxicity of mitoxantrone with or without KD025 treatment in leukemia blast cells derived from patients with leukemia were analyzed (Fig. 2). The results demonstrated that 4 of 9 patient samples displayed detectable ABCG2 expression (patient nos. 1, 5, 6 and 7); the expression levels of ABCG2 in patient nos. 5 and 7 were significantly higher than the average of ABCG2 expression in the four samples, while the leukemic blast cells derived from patient nos. 1 and 6 with low expression levels of ABCG2 were excluded from subsequent analyses due to possible experimental errors $(\mathrm{P}<0.05$; Fig. $2 \mathrm{~A}$ and $\mathrm{B})$. Treatment of leukemic blast cells with $2.5 \mu \mathrm{M}$ KD025 effectively increased their sensitivity to the cytotoxicity of mitoxantrone in leukemic blast cells derived from patient nos. 5 and 7 (Fig. 2C and D, respectively). The results suggested that the combined use of KD025 and mitoxantrone may result in effective clinical effects.

KD025 increases the accumulation of $\left[{ }^{3} \mathrm{H}\right]$-mitoxantrone and antagonizes its efflux in ABCG2-overexpressing leukemia cell lines. Transporter inhibitors typically enhance anticancer activity through preventing transporter-mediated efflux, which leads to an increase in the accumulation of the intracellular drug (29). To investigate the potential mechanism of KD025 sensitizing ABCG2-overexpressing leukemia cells to antineoplastic drugs, the intracellular levels of $\left[{ }^{3} \mathrm{H}\right]$-mitoxantrone were analyzed in the presence or absence of KD025 treatment.KD025 treatment significantly increased the intracellular accumulation levels of $\left[{ }^{3} \mathrm{H}\right]$-mitoxantrone in HL60/ABCG2 cells (Fig. 3B). Meanwhile, the accumulative effect of $\left[{ }^{3} \mathrm{H}\right]$-mitoxantrone following $1 \mu \mathrm{M} \mathrm{KD} 025$ treatment was similar to that with $2.5 \mu \mathrm{M}$ FTC. In addition, KD025 treatment significantly reduced the efflux of $\left[{ }^{3} \mathrm{H}\right]$-mitoxantrone in HL60/ABCG2 cells compared with in cells without KD025 treatment (Fig. 3E). Similarly, pretreatment of KD025 also effectively improved the intracellular levels of $\left[{ }^{3} \mathrm{H}\right]$-mitoxantrone and decreased its efflux in K562/ABCG2 cells (Fig. 3B, D and F). However, KD025 treatment did not significantly alter the efflux or accumulation of $\left[{ }^{3} \mathrm{H}\right]$-mitoxantrone in the parental HL60 or K562 cells (Fig. 3A and C). These results indicated that KD025 treatment may increase the intracellular accumulation of $\left[{ }^{3} \mathrm{H}\right]$-mitoxantrone and antagonize its efflux in ABCG2-overexpressing leukemia cell lines in a concentration-dependent manner.

KD025 does not alter the expression levels and subcellular locations of ABCG2. To determine the effect of KD025 treatment on the expression levels and subcellular locations of ABCG2, western blotting and immunofluorescence assays were performed on HL60/ABCG2 cells. ABCG2 protein expression levels were not altered following $72 \mathrm{~h}$ of treatment 
A
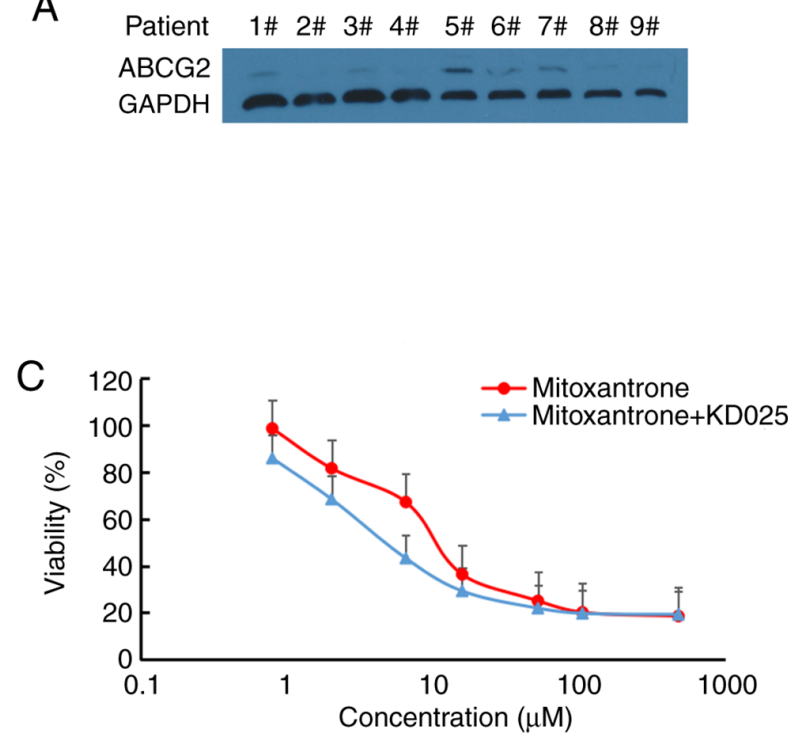
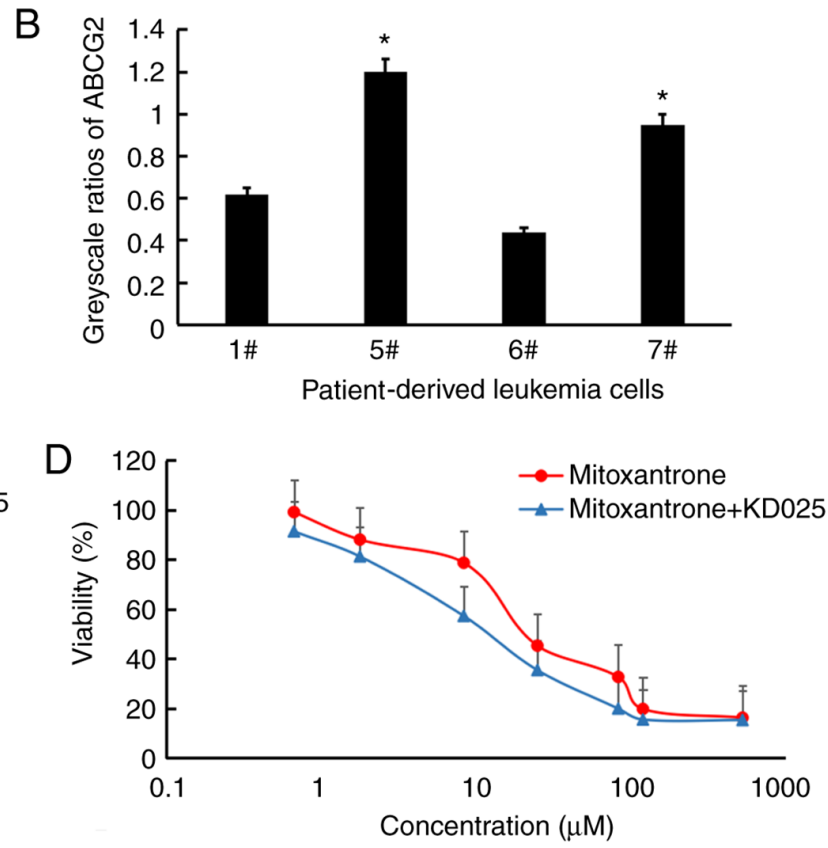

Figure 2. KD025 enhances the cytotoxicity of mitoxantrone on patient-derived ABCG2-overexpressing leukemia blast cells. Bone narrow samples were collected from 9 patients newly diagnosed with leukemia. (A) ABCG2 expression levels in leukemia blast cells derived from patients were detected by western blotting. (B) Patient nos. 1, 5, 6 and 7 displayed detectable ABCG2 expression. Samples from two patients (nos. 5 and 7) exhibited higher levels of ABCG2 protein than the average of ABCG2 expression in the four samples (patient nos. 1, 5,6 and 7). The expression levels of GAPDH were used as loading controls. The protein expression levels were quantified using gray value analysis software. Enhancement by KD025 on mitoxantrone cytotoxicity in primary cultures of leukemia blasts from (C) patient no. 5 and (D) patient no. 7 with high ABCG2 levels. Data are expressed as the mean \pm standard deviation from three independent experiments. ${ }^{~} \mathrm{P}<0.05$ vs. the average of ABCG2 expression in patient nos. 1, 5, 6 and 7 (represented by a dotted line). ABCG2, ATP-binding cassette transporter ABCG2.

A

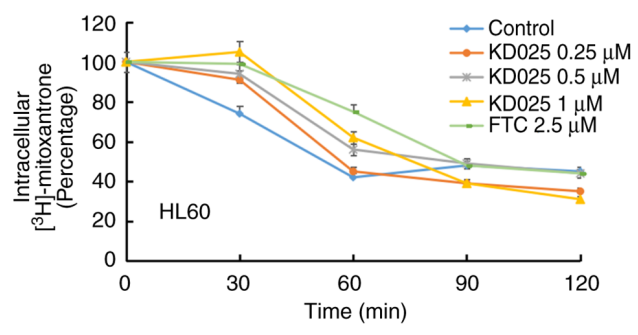

C

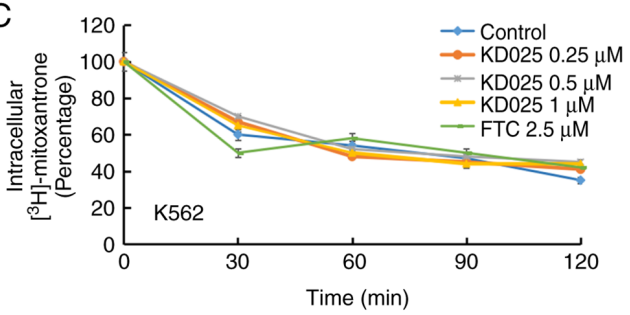

E $=$ Control $₫ \mathrm{KD} 0250.25 \mu \mathrm{M}=\mathrm{KD} 0250.5 \mu \mathrm{M}=\mathrm{KD} 0251 \mu \mathrm{M}=\mathrm{FTC} 2.5 \mu \mathrm{M}$

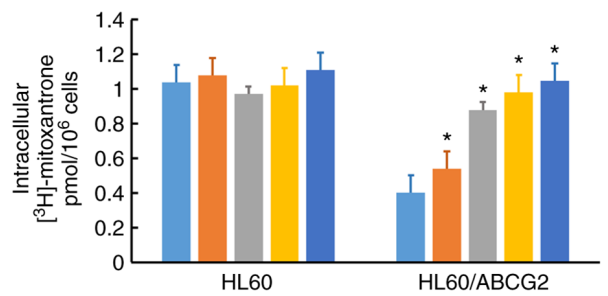

B

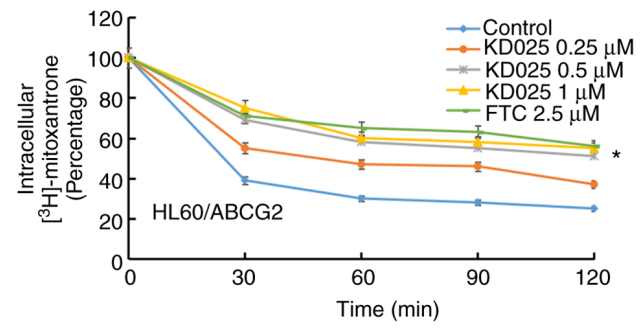

$\mathrm{D}$

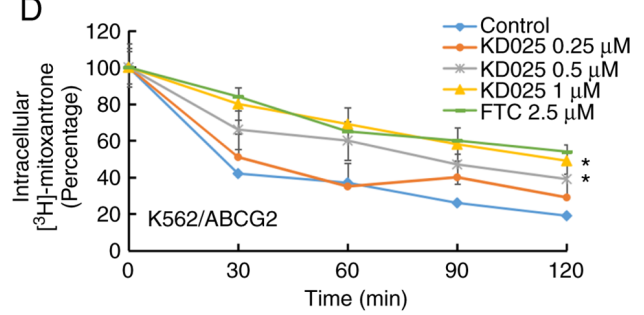

$\mathrm{F} \quad \mathrm{m}$ Control $=\mathrm{KD} 0250.25 \mu \mathrm{M}=\mathrm{KD} 0250.5 \mu \mathrm{M}=\mathrm{KD} 0251 \mu \mathrm{M}=\mathrm{FTC} 2.5 \mu \mathrm{M}$

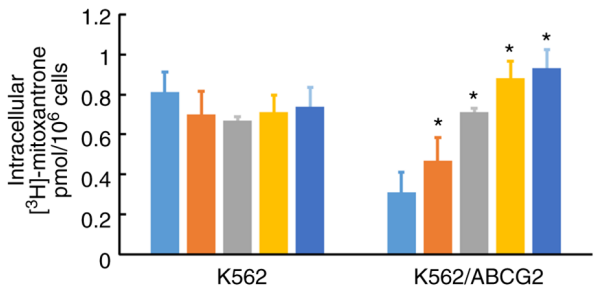

Figure 3. Effects of KD025 on intracellular levels and efflux of $\left[{ }^{3} \mathrm{H}\right]$-mitoxantrone. Accumulation levels of $\left[{ }^{3} \mathrm{H}\right]$-mitoxantrone in (A) HL60 and its ABCG2-overexpressing cell line (B) HL60/ABCG2 upon treatment with $0.25,0.5$ and $1 \mu \mathrm{M} \mathrm{KD025}$ and $2.5 \mu \mathrm{M} \mathrm{FTC}$. Accumulation levels of $\left[{ }^{3} \mathrm{H}\right]$-mitoxantrone in (C) K562 and its ABCG2-overexpressing cell line (D) K562/ABCG2 upon treatment with 0.25, 0.5,1 $\mu \mathrm{M} \mathrm{KD} 025$ and $2.5 \mu \mathrm{M}$ FTC. (E and F) The effects of KD025 on the efflux $\left[{ }^{3} \mathrm{H}\right]$-mitoxantrone in drug-resistant and their parental drug-sensitive cell lines. Data are expressed as the mean \pm standard deviation of three independent experiments. " $\mathrm{P}<0.05$ vs. control. ABCG2, ATP-binding cassette transporter ABCG2; FTC, fumitremorgin C. 
A

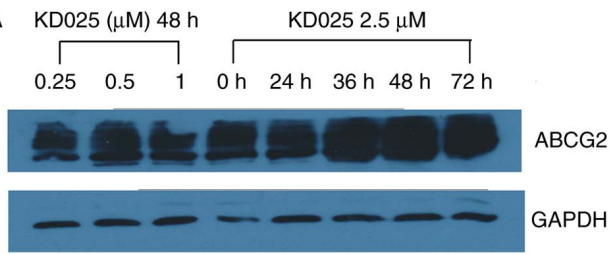

B

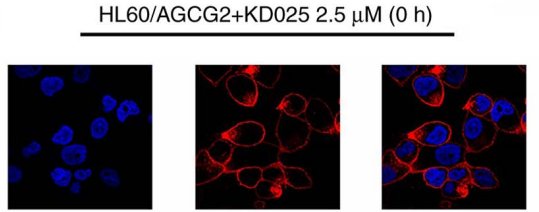

HL6/ABCG2+KD025 $2.5 \mu \mathrm{M}(72 \mathrm{~h})$

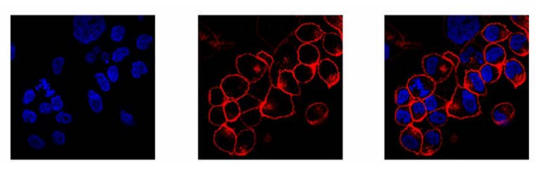

Figure 4. Effects of KD025 on expression levels and subcellular localization of ABCG2 protein in HL60/ABCG2 cells. (A) Western blotting was performed to detect ABCG2 expression. HL60/ABCG2 cells were treated with different concentrations KD025 for $48 \mathrm{~h}$ or $2.5 \mu \mathrm{M}$ KD025 for up to $72 \mathrm{~h}$. (B) Immunofluorescence staining (magnification, $\mathrm{x} 400$ ) was used to investigate the subcellular localization of ABCG2 in HL60/ABCG2 cells treated with $2.5 \mu \mathrm{M} \mathrm{KD} 025$ for 0 or $72 \mathrm{~h}$. ABCG2 staining is shown in red. Fluorescent DAPI (blue) was used to counterstain the nuclei. ABCG2, ATP-binding cassette transporter ABCG2.

with $2.5 \mu \mathrm{M}$ KD025 or with treatment of different concentrations KD025 for $48 \mathrm{~h}$ in HL60/ABCG2 cell lines (Fig. 4A). In addition, there were no significant changes identified in the cellular localizations of the ABCG2 transporters following the treatment with $1 \mu \mathrm{M}$ KD025 for up to $72 \mathrm{~h}$ in HL60/ABCG2 cell lines (Fig. 4B). The present results suggested that the reversal effects of KD025 were not accomplished by altering the expression levels nor changing the intracellular localization of ABCG2 in HL60/ABCG2 cell lines.

\section{Discussion}

Chemotherapy is the most effective therapeutic method for patients with malignant leukemia, and the development of standard induction therapy has resulted in complete hematological remission (2). However, in recent decades, the survival rate of leukemia has remained very low (30), without any significant improvements being made. The main cause is that most patients with leukemia are either resistant to any initial treatment or acquire resistance to chemotherapy (31). Thus, MDR, which is described as the resistance to structurally and functionally unrelated drugs, remains a challenge to the successful treatment of patients with malignant leukemia undergoing chemotherapy (32). MDR that occurs at the molecular level has been reported to be more difficult to overcome due to the reduced toxicity of intracellular antitumor drugs (33). One mechanism of cellular MDR is the overexpression of the ABC superfamily of membrane transporters; aberrant activation of the drug efflux pumps of the $\mathrm{ABC}$ protein effectively reduce intracellular concentration of antineoplastic drugs (34). It was reported that ABCB1 (also known as P-glycoprotein and MDR1), ABCC1 (MRP1) and ABCG2 (BCRP) were closely associated with MDR in numerous types of cancer cells, such as high-grade serous ovarian carcinoma, refractory acute lymphoblastic leukemia and anaplastic lymphoma kinase-rearranged lung cancer (35). These transporters have the ability to efflux a large number of antitumor drugs from the cells, but each transporter has its own unique substrates (4). Therefore, inhibiting the efflux function of these proteins may provide more promising therapeutic effects for patients with leukemia.

Notably, the BCRP gene encoding ABCG2 has demonstrated enhanced clinical significance in malignant leukemia. For example, a study on AML revealed that $33 \%$ of AML blasts had upregulated BCRP expression levels and were inversely correlated with disease prognosis and overall survival (36). In addition, ABCG2 has been widely recognized as a promising therapeutic target for eradication of LSCs, since ABCG2 is highly enriched in LSCs and serves a crucial role in the differentiation, proliferation and self-renewal of LSCs (37). Although intensive methods and drugs have been designed to inhibit ABCG2, unfortunately, even with the most advanced treatments to date, the reversal of ABCG2-mediated MDR remains unsatisfactory and the relapse risk of patients with leukemia remains high in the first two years (38). Furthermore, as of yet, appropriate inhibitors of ABCG2 are lacking, since these agents are not very potent or are toxic, and their ability to inhibit ABCG2 has not been verified in patients (4). Thus, exploiting effective and safe ABCG2 transporter inhibitors is currently the considered method to improve the clinical efficacy of leukemia chemotherapy.

ROCK1 and ROCK2, and their isoform-mediated signals, have been reported to be responsible for cell morphology, adhesion and migration (39). Furthermore, the ROCK pathway was also discovered to serve an important role in physiological conditions and the abnormal activation of myeloproliferative diseases (40). A previous study demonstrated that ROCK inhibition effectively reduced leukemic cell proliferation (41). Therefore, the deregulation of ROCK signaling is emerging as a potential key target in leukemia. KD025 is a highly selective inhibitor of ROCK2 and has entered Phase I clinical trials for psoriasis (15), idiopathic pulmonary fibrosis and systemic sclerosis (42). A previous study revealed that KD025 treatment inhibited the adipocyte differentiation at the intermediate stage in 3T3-L1 preadipocytes (43). Moreover, KD025 was suggested to restore impaired immune homeostasis and serve a role in autoimmunity therapy (44). The present study indicated that KD025 treatment may be an effective inhibitor for reversing MDR in leukemia cell lines. These results were consistent with other previous studies on the ROCK signaling pathway in leukemia $(41,45)$. However, the reversal efficiency and mechanism of KD025 treatment in ABCG2-mediated MDR remains unclear.

Data from the present study revealed that KD025 treatment may interact with ABCG2 in leukemia cells. Cytotoxicity assays demonstrated that KD025 treatment significantly altered the sensitivity of the ABCG2 substrates mitoxantrone and topotecan in ABCG2-overexpressing leukemia cells in a dose-dependent manner. However, KD025 treatment did not increase the cytotoxicity of cisplatin, which is not a substrate of ABCG2. Furthermore, no significant changes were identified in the antitumor effects in the drug-sensitive parental 
leukemia HL60 and K562 cell lines. These data suggested that the combination of KD025 treatment with chemotherapeutic drugs may exert a preferable antineoplastic effect. Moreover, the present study also investigated the efficiency of KD025 in patient-derived leukemia blast cells. The results indicated that KD025 treatment enhanced the cytotoxicity of mitoxantrone in ABCG2-overexpressing samples. The significant inhibitory effects of KD025 treatment on leukemia cells also prompted the determination of its underlying mechanism. The drug accumulation assay demonstrated that KD025 treatment effectively improved the intracellular accumulation of mitoxantrone and antagonized its efflux in ABCG2-overexpressing leukemia cells. It has been previously proposed that ABCG2 inhibitors are divided into two subtypes: Those only inhibiting ABCG2 activity (most ABCG2 inhibitors) and those that inhibit ABCG2 activity in addition to reducing the expression levels of ABCG2 (for example afatinib) (46). Thus, the present study investigated the effects of KD025 treatment at different concentrations on the protein expression levels and intracellular locations of ABCG2 in leukemia cells through western blotting and immunofluorescence assays, respectively. The results revealed that KD025 treatment did not alter the expression levels or location of ABCG2 in HL60/ABCG2 cell lines. Therefore, KD025 may exert its reversal effect by directly inhibiting ABCG2 activity. Generally, ABCG2 exerts its efflux functions depending on the ATPase activity, of which the ATPase activity of ABC transporters is stimulated in the presence of transport substrates $(29,32)$. Most reversal drugs block drug transport by acting as competitive substrates that occupy the valid sites to prevent the drug transport out of the cell $(9,47)$. A recent report suggested that KD025 may decrease the activity of ATP in pulmonary microvascular endothelial cells (48). Thus, KD025 treatment may exert an inhibitory effect on ABCG2 in leukemia cells through competitive substrate transport blockade.

In conclusion, the results of the present study suggested that KD025 treatment may significantly improve the sensitivity of leukemia cells to chemotherapeutics by antagonizing the efflux function of ABCG2. Therefore, KD025 treatment combined with ABCG2 substrate antitumor drugs may be beneficial for the treatment of MDR in patients with leukemia. While the anti-tumor efficacy of the drug combination has been demonstrated, further studies are still warranted to determine whether KD025 exerts effects on LSCs or has any cell type or tissue specificity.

\section{Acknowledgements}

Not applicable.

\section{Funding}

No funding was received.

\section{Availability of data and materials}

The datasets used and/or analyzed during the current study are available from the corresponding author on reasonable request.

\section{Authors' contributions}

$\mathrm{XX}$ and JP designed the research theme. WJ, XZ and RC designed methods and experiments, performed the laboratory experiments, analyzed the data, interpreted the results and wrote the paper. WL, XY, WY and MZ co-designed the experiments and discussed the analyses, interpretation and presentation of data. All authors read and approved the final manuscript.

\section{Ethics approval and consent to participate}

The experimental protocol for patient samples studies was reviewed and approved by the Ethics Review Committee of Sun Yat-Sen University. All patients provided written informed consent.

\section{Patient consent for publication}

Not applicable.

\section{Competing interests}

The authors declare that they have no competing interests.

\section{References}

1. Kayser S and Levis MJ: Advances in targeted therapy for acute myeloid leukaemia. Br J Haematol 180: 484-500, 2018.

2. De Kouchkovsky I and Abdul-Hay M: 'Acute myeloid leukemia: A comprehensive review and 2016 update'. Blood Cancer J 6: e441, 2016

3. Sarkadi B, Homolya L, Szakács G and Váradi A: Human multidrug resistance $\mathrm{ABCB}$ and $\mathrm{ABCG}$ transporters: Participation in a chemoimmunity defense system. Physiol Rev 86: 1179-1236, 2006.

4. Robey RW, Pluchino KM, Hall MD, Fojo AT, Bates SE and Gottesman MM: Revisiting the role of ABC transporters in multidrug-resistant cancer. Nat Rev Cancer 18: 452-464, 2018.

5. Shaffer BC, Gillet JP, Patel C, Baer MR, Bates SE and Gottesman MM: Drug resistance: Still a daunting challenge to the successful treatment of AML. Drug Resist Updat 15: 62-69, 2012.

6. Gottesman MM, Fojo T and Bates SE: Multidrug resistance in cancer: Role of ATP-dependent transporters. Nat Rev Cancer 2: 48-58, 2002.

7. Steinbach D, Sell W, Voigt A, Hermann J, Zintl F and Sauerbrey A: BCRP gene expression is associated with a poor response to remission induction therapy in childhood acute myeloid leukemia. Leukemia 16: 1443-1447, 2002.

8. Yano K, Okabe C, Fujii K, Kato Y and Ogihara T: Regulation of breast cancer resistance protein and P-glycoprotein by ezrin, radixin and moesin in lung, intestinal and renal cancer cell lines. J Pharm Pharmacol 72: 575-582, 2020.

9. Dai CL, Tiwari AK, Wu CP, Su XD, Wang SR, Liu DG, Ashby CJ Jr, Huang Y, Robey RW, Liang YJ, et al: Lapatinib (Tykerb, GW572016) reverses multidrug resistance in cancer cells by inhibiting the activity of ATP-binding cassette subfamily B member 1 and $\mathrm{G}$ member 2. Cancer Res 68: 7905-7914, 2008.

10. Strope JD, Peer CJ, Sissung TM, Hall OM, Huang PA, Harris EM, Gustafson KR, Henrich CJ, Sigano DM, Pauly GT, et al: Botryllamide $\mathrm{G}$ is an ABCG2 inhibitor that improves lapatinib delivery in mouse brain. Cancer Biol Ther 21: 223-230, 2020.

11. Yeheskely-Hayon D, Regev R, Eytan GD and Dann EJ: The tyrosine kinase inhibitors imatinib and AG957 reverse multidrug resistance in a chronic myelogenous leukemia cell line. Leuk Res 29: 793-802, 2005.

12. Wilson CS, Davidson GS, Martin SB, Andries E, Potter J, Harvey R, Ar K, Xu Y, Kopecky KJ, Ankerst DP, et al: Gene expression profiling of adult acute myeloid leukemia identifies novel biologic clusters for risk classification and outcome prediction. Blood 108: 685-696, 2006. 
13. Ding XW, Wu JH and Jiang CP: ABCG2: A potential marker of stem cells and novel target in stem cell and cancer therapy. Life Sci 86: 631-637, 2010.

14. Mo W and Zhang JT: Human ABCG2: Structure, function, and its role in multidrug resistance. Int J Biochem Mol Biol 3: 1-27, 2012.

15. Yiu ZZ and Warren RB: Novel oral therapies for psoriasis and psoriatic arthritis. Am J Clin Dermatol 17: 191-200, 2016.

16. Rozo C, Chinenov Y, Maharaj RK, Gupta S, Leuenberger L, Kirou KA, Bykerk VP, Goodman SM, Salmon JE and Pernis AB: Targeting the RhoA-ROCK pathway to reverse T-cell dysfunction in SLE. Ann Rheum Dis 76: 740-747, 2017.

17. Diep D, Hong K, Khun T, Zheng M, Ul-Haq A, Jun HS, Kim YB and Chun KH: Anti-adipogenic effects of KD025 (SLx-2119), a ROCK2-specific inhibitor, in 3T3-L1 cells. Sci Rep 8: 2477 , 2018.

18. Zanin-Zhorov A, Weiss JM, Nyuydzefe MS, Chen W, Scher JU, Mo R, Depoil D, Rao N, Liu B, Wei J, et al: Selective oral ROCK2 inhibitor down-regulates IL-21 and IL-17 secretion in human T cells via STAT3-dependent mechanism. Proc Natl Acad Sci USA 111: 16814-16819, 2014.

19. Sugimoto Y, Tsukahara S, Imai Y, Sugimoto Y, Ueda K and Tsuruo T: Reversal of breast cancer resistance protein-mediated drug resistance by estrogen antagonists and agonists. Mol Cancer Ther 2: 105-112, 2003.

20. Imai $Y$, Tsukahara S, Asada $S$ and Sugimoto $Y$ : Phytoestrogens/flavonoids reverse breast cancer resistance protein/ABCG2-mediated multidrug resistance. Cancer Res 64: 4346-4352, 2004.

21. Luo F, Luo M, Rong QX, Zhang H, Chen Z, Wang F, Zhao HY and Fu LW: Niclosamide, an antihelmintic drug, enhances efficacy of PD-1/PD-L1 immune checkpoint blockade in Non-smal cell lung cancer. J Immunother Cancer 7: 245, 2019.

22. Wang F, Wang XK, Shi CJ, Zhang H, Hu YP, Chen YF and Fu LW: Nilotinib enhances the efficacy of conventional chemotherapeutic drugs in $\mathrm{CD}_{34}{ }^{+} \mathrm{CD} 38^{-}$stem cells and $\mathrm{ABC}$ transporter overexpressing leukemia cells. Molecules 19 3356-3375, 2014.

23. Riss TL, Moravec RA, Niles AL, Duellman S, Benink HA, Worzella TJ and Minor L: Cell viability assays. In: Assay Guidance Manual [Internet]. Bethesda (MD), Eli Lilly \& Company and the National Center for Advancing Translational Sciences; May 1, 2004.

24. Percival ME, Lai C, Estey E and Hourigan CS: Bone marrow evaluation for diagnosis and monitoring of acute myeloid leukemia. Blood Rev 31: 185-192, 2017.

25. Zhang H, Patel A, Ma SL, Li XJ, Zhang YK, Yang PQ, Kathawala RJ, Wang YJ, Anreddy N, Fu LW and Chen ZS: In vitro, in vivo and ex vivo characterization of ibrutinib: A potent inhibitor of the efflux function of the transporter MRP1. Br J Pharmacol 171: 5845-5857, 2014

26. Li J, Kumar P, Anreddy N, Zhang YK, Wang YJ, Chen Y, Talele TT, Gupta K, Trombetta LD and Chen ZS: Quizartinib (AC220) reverses ABCG2-mediated multidrug resistance: In vitro and in vivo studies. Oncotarget 8: 93785-93799, 2017.

27. Wang XK, To KK, Huang LY, Xu JH, Yang K, Wang F, Huang ZC, Ye $S$ and Fu LW: Afatinib circumvents multidrug resistance via dually inhibiting ATP binding cassette subfamily G member 2 in vitro and in vivo. Oncotarget 5: 11971-11985, 2014.

28. Ejendal KF and Hrycyna CA: Multidrug resistance and cancer: The role of the human ABC transporter ABCG2. Curr Protein Pept Sci 3: 503-511, 2002

29. Shi Z, Tiwari AK, Shukla S, Robey RW, Kim IW, Parmar S, Bates SE, Si QS, Goldblatt CS, Abraham I, et al: Inhibiting the function of ABCB1 and ABCG2 by the EGFR tyrosine kinase inhibitor AG1478. Biochem Pharmacol 77: 781-793, 2009.

30. Zhang W, Sun S, Zhang W and Shi Z: Polymorphisms of ABCG2 and its impact on clinical relevance. Biochem Biophys Res Commun 503: 408-413, 2018.

31. Takeshita A: Efficacy and resistance of gemtuzumab ozogamicin for acute myeloid leukemia. Int J Hematol 97: 703-716, 2013.

32. Tiwari AK, Sodani K, Dai CL, Ashby CJ and Chen ZS: Revisiting the ABCs of multidrug resistance in cancer chemotherapy. Curr Pharm Biotechnol 12: 570-594, 2011.
33. Shi Z, Liang YJ, Chen ZS, Wang XW, Wang XH, Ding Y, Chen LM, Yang XP and Fu LW: Reversal of MDR1/ P-glycoprotein-mediated multidrug resistance by vector-based RNA interference in vitro and in vivo. Cancer Biol Ther 5: 39-47, 2006.

34. Robey RW, To KK, Polgar O, Dohse M, Fetsch P, Dean M and Bates SE: ABCG2: A perspective. Adv Drug Deliv Rev 61: 3-13, 2009.

35. Szakacs G, Varadi A, Ozvegy-Laczka C and Sarkadi B: The role of $\mathrm{ABC}$ transporters in drug absorption, distribution, metabolism, excretion and toxicity (ADME-Tox). Drug Discov Today 13: 379-393, 2008.

36. Chen L, Manautou JE, Rasmussen TP and Zhong XB Development of precision medicine approaches based on inter-individual variability of BCRP/ABCG2. Acta Pharm Sin B 9: 659-674, 2019.

37. Lou $\mathrm{H}$ and Dean M: Targeted therapy for cancer stem cells: The patched pathway and ABC transporters. Oncogene 26: 1357-1360, 2007.

38. Alkharabsheh $\mathrm{O}$ and Frankel AE: Clinical activity and tolerability of SL-401 (Tagraxofusp): Recombinant diphtheria toxin and interleukin-3 in hematologic malignancies. Biomedicines 7: 6, 2019.

39. Borin TF, Arbab AS, Gelaleti GB, Ferreira LC, Moschetta MG, Jardim-Perassi BV, Iskander AS, Varma NR, Shankar A, Coimbra VB, et al: Melatonin decreases breast cancer metastasis by modulating Rho-associated kinase protein-1 expression. J Pineal Res 60: 3-15, 2016

40. Rocca S, Carra G, Poggio P, Morotti A and Brancaccio M: Targeting few to help hundreds: JAK, MAPK and ROCK pathways as druggable targets in atypical chronic myeloid leukemia. Mol Cancer 17: 40, 2018.

41. Takahashi N, Nobusue H, Shimizu T, Sugihara E, Yamaguchi-Iwai S, Onishi N, Kunitomi H, Kuroda T and Saya H: ROCK inhibition induces terminal adipocyte differentiation and suppresses tumorigenesis in chemoresistant osteosarcoma cells. Cancer Res 79: 3088-3099, 2019.

42. Yoon JH, Nguyen TT, Duong VA, Chun KH and Maeng HJ: Determination of KD025 (SLx-2119), a selective ROCK2 inhibitor, in rat plasma by high-performance liquid chromatography-tandem mass spectrometry and its pharmacokinetic application. Molecules 25: 1369, 2020.

43. Diep D, Duong K, Choi H, Jun HS and Chun KH: KD025 (SLx-2119) suppresses adipogenesis at intermediate stage in human adipose-derived stem cells. Adipocyte 8: 114-124, 2019.

44. Flynn R, Paz K, Du J, Reichenbach DK, Taylor PA, Panoskaltsis-Mortari A, Vulic A, Luznik L, MacDonald KK, Hill GR, et al: Targeted Rho-associated kinase 2 inhibition suppresses murine and human chronic GVHD through a Stat3-dependent mechanism. Blood 127: 2144-2154, 2016.

45. D'Amato L, Dell'Aversana C, Conte M, Ciotta A, Scisciola L, Carissimo A, Nebbioso A and Altucci L: ARHGEF3 controls HDACi-induced differentiation via RhoA-dependent pathways in acute myeloid leukemias. Epigenetics 10: 6-18, 2015.

46. Wang XK, He JH, Xu JH, Ye S, Wang F, Zhang H, Huang ZC, To KK and Fu LW: Afatinib enhances the efficacy of conventional chemotherapeutic agents by eradicating cancer stem-like cells. Cancer Res 74: 4431-4445, 2014.

47. Nakamura Y, Oka M, Soda H, Shiozawa K, Yoshikawa M, Itoh A, Ikegami Y, Tsurutani J, Nakatomi K, Kitazaki T, et al: Gefitinib ('Iressa', ZD1839), an epidermal growth factor receptor tyrosine kinase inhibitor, reverses breast cancer resistance protein/ABCG2-mediated drug resistance. Cancer Res 65: 1541-1546, 2005.

48. Lee JY, Stevens RP, Kash M, Zhou C, Koloteva A, Renema P, Paudel SS and Stevens T: KD025 shifts pulmonary endothelial cell bioenergetics and decreases baseline lung permeability. Am J Respir Cell Mol Biol: Jul 6, 2020 (Epub ahead of print).

This work is licensed under a Creative Commons Attribution-NonCommercial-NoDerivatives 4.0 International (CC BY-NC-ND 4.0) License. 